\title{
Reusing Cow Manure for the Production of Activated Carbon Using Potassium Hydroxide (KOH) Activation Process and Its Liquid-Phase Adsorption Performance
}

\author{
Wen-Tien Tsai ${ }^{1, *}$, Po-Cheng Huang ${ }^{2}$ and Yu-Quan Lin ${ }^{2}$ \\ 1 Graduate Institute of Bioresources, National Pingtung University of Science and Technology, \\ Pingtung 912, Taiwan \\ 2 Department of Environmental Science and Engineering, National Pingtung University of Science and \\ Technology, Pingtung 912, Taiwan; mike299123@gmail.com (P.-C.H.); wsx55222525@gmail.com (Y.-Q.L.) \\ * Correspondence: wttsai@mail.npust.edu.tw
}

Received: 18 September 2019; Accepted: 8 October 2019; Published: 14 October 2019

\begin{abstract}
In this work, cow manure (CM) was reused as a potential precursor in the production of activated carbon (AC) using a potassium hydroxide activation process at different temperatures (i.e., 500, 600 and $700^{\circ} \mathrm{C}$ ). The optimal activated carbon from cow manure (CM-AC) with high specific surface area $\left(c a .950 \mathrm{~m}^{2} / \mathrm{g}\right)$ was further investigated for its adsorption performance in the removal of a model compound (i.e., methylene blue) from aqueous solution with various initial concentrations and adsorbent dosages at $25^{\circ} \mathrm{C}$. It was found that the resulting $\mathrm{AC}$ could be an effective adsorbent for removal of cationic dye from aqueous solution in comparison with a commercial coal-based AC. Based on the observations of the energy dispersive X-ray spectroscopy and Fourier transform infrared spectroscopy (FTIR), the CM-AC adsorbent has a stronger interaction with the cationic compound due to its more oxygen-containing complex on the surface. Furthermore, the adsorption kinetic parameters fitted using the pseudo-second order model with high correlations were in accordance with their pore properties.
\end{abstract}

Keywords: cow manure; chemical activation process; activated carbon; pore property; cationic pollutant; adsorption performance

\section{Introduction}

Water pollution caused by organic pollutants (e.g., dye, pesticide) is a serious issue because it can degrade water quality and render it toxic to public health and the environment. In general, there are two advanced treatment processes for removal of contaminants from the water bodies [1]. One belongs to destructive processes such as ozone oxidation and the Fenton method [2]. Other processes are recuperative. Among the recuperative process, adsorption may be the most used method due to its features of easy operation, high efficiency and simple design [3]. Therefore, carbon adsorption by granular activated carbon (GAC) or powdered activated carbon (PAC) has been considered as one of the best available technologies in the water and wastewater treatment processes for removal of organic pollutants $[4,5]$. However, the adsorption process is not a low-cost method because commercial activated carbon (AC) products have higher prices and the regeneration or disposal when they are exhausted will generate additional issues. In recent years, the use of low-cost precursors in the preparation of AC for the removal of various types of pollutants from water and wastewater has been reviewed [6-11]. Obviously, utilizing organic wastes or residues as AC precursors poses several advantages such as climate change 
mitigation (reduction of greenhouse gas emissions), biomass energy production (reusing exhausted AC as auxiliary fuel), and waste management (improvement of environmental quality).

Cattle manure or dung is a renewable resource because it mainly comes from the undigested residue of cellulose-based feeds being excreted by livestock animal species such as cow (dairy cattle) and bull. Generally, cattle manure was converted into fertilizer or soil amendment by composting because composted manure contains many dissolved organic matter (DOM) fractions [12]. Without proper treatment or management, it can cause some environmental problems, including air quality deterioration (e.g., odor), public hazards (e.g., infectious pathogen and asphyxia poisoning), greenhouse gas emissions (e.g., carbon dioxide and methane), and water pollution (e.g., eutrophication) [13]. Due to its high carbon content, this biomass resource can be thermally converted into various forms of energy sources (i.e., heat or electricity) [13-20] and biochar used as an adsorbent [21-26], but this approach may encounter some drawbacks, including low energy yield and air pollutants (e.g., sulfur oxides, nitrogen oxides, carbon monoxide and particulate matters) being emitted [27]. In order to upgrade its additional value of reuse, the production of AC from cow manure and its adsorption applications have been reported in recent years [28-36].

AC may be the frequently used carbon material in different state-of-the-art applications due to its physical and electrochemical properties, including high surface area, wide pore distribution and large specific capacitance [10,37]. In general, there are two methods for producing AC: physical and chemical activation processes [38]. Physical activation involves carbonization and activation in a single step or two separate steps at higher temperature under the atmosphere of gasification gas (i.e., steam or carbon dioxide). The resulting $\mathrm{AC}$ possesses poor pore properties as compared to $\mathrm{AC}$ prepared from chemical activation. By contrast, AC production using chemical activation is performed in a single step at a lower temperature using precursor impregnated with chemical reagents (i.e., potassium hydroxide, phosphoric acid, or zinc chloride). However, some impurities like potassium (K), zinc (Zn) or phosphorus $(\mathrm{P})$, depending on the chemical reagents used, can be found in $\mathrm{AC}$ products, thus raising the production costs due to the additional processes for removing these residual activation reagents. As reviewed above, little research has performed the reuse of cow manure or cattle manure as a feedstock for producing AC. In the reports by Machida's group [28-36], they first studied the production of AC from cattle manure compost (CMC) using chemical activation with zinc chloride $\left(\mathrm{ZnCl}_{2}\right)$. Furthermore, the CMC-derived activated carbon was tested to evaluate the liquid-phase adsorption performances of various adsorption targets, including phenol, methylene blue, water vapor, metal ions (i.e., $\mathrm{Cu}, \mathrm{Pb}$ ), and 2-methylisoborneol. In another recent study by $\mathrm{Li}$ et al. [36], AC was also produced from cow manure using chemical activators like potassium carbonate $\left(\mathrm{K}_{2} \mathrm{CO}_{3}\right)$ and $\mathrm{ZnCl}_{2}$, showing that the values of specific surface area range from 114 to $893 \mathrm{~m}^{2} / \mathrm{g}$. The authors also treated the wastewater from a cow farm with the resulting ACs.

Although many studies have reported the utilization of cow manure as a precursor for producing ACs [28-36], they were mostly produced using chemical activation with $\mathrm{ZnCl}_{2}$ and potassium carbonate $\left(\mathrm{K}_{2} \mathrm{CO}_{3}\right)$. On the other hand, the adsorption performances of the resulting AC products were not compared with commercial AC. Thus, the main purposes of this paper were to produce highly porous $\mathrm{AC}$ from cow manure using a potassium hydroxide $(\mathrm{KOH})$ activation process at different temperatures. Subsequently, the resulting AC with the optimal pore properties was performed to evaluate its effectiveness in the removal of cationic dye (i.e., methylene blue) from the aqueous solution. Finally, the adsorption performances for the removal of methylene blue from aqueous solution were compared between the CM-based AC and commercial coal-based AC.

\section{Materials and Methods}

\subsection{Materials}

The precursor for producing AC was obtained from the Livestock Research Institute (Tainan, Taiwan). The cow (Holstein) manure (CM) sample was dried using a hot air circulating oven for about one 
week. The methods for characterizing its main thermochemical properties were similar to the previous studies [26,39], showing that the dried CM is composed mainly of volatile matter (about $80 \mathrm{wt} \%$ ) with $42 \mathrm{wt} \%$ carbon. The potassium hydroxide ( $\mathrm{KOH}$; Merck Co., Darmstadt, Germany) was used to impregnate $\mathrm{CM}$ to produce $\mathrm{AC}$ using chemical activation. As methylene blue was commonly selected as a probe compound for determining the adsorption capacity of AC quickly [37], this cationic dye, which was purchased from Merck Co., was used as an organic pollutant target in the work. In order to compare the adsorption performance of the resulting AC with commercial AC, a product (Filtrasorb-300; Calgon Carbon Co., Moon Township, PA, USA) for liquid-phase applications was used to remove methylene blue (MB) at the same adsorption conditions.

\subsection{Impregnation and Activation Experiments}

The preparation of $\mathrm{AC}$ from $\mathrm{CM}$ was carried out using the $\mathrm{KOH}$ activation process referred to in a previous study [40]. In the present study, the $\mathrm{CM}$ impregnated with $\mathrm{KOH}(\mathrm{KOH}-\mathrm{CM})$ was described as follows: $10 \mathrm{~g}$ of $\mathrm{CM}$ was mixed with $5 \mathrm{~g}$ of $\mathrm{KOH}$ in $150 \mathrm{~cm}^{3}$ of de-ionized water and stirred using a magnetic bar at about $75^{\circ} \mathrm{C}$ for $30 \mathrm{~min}$, and then decanted into the supernatant prior to being dried at about $105^{\circ} \mathrm{C}$ for $24-48 \mathrm{~h}$. Subsequently, the $\mathrm{KOH}-\mathrm{CM}$ (about $3 \mathrm{~g}$ ) was activated by passing nitrogen gas $\left(500 \mathrm{~cm}^{3} / \mathrm{min}\right)$ at a heating rate of about $10^{\circ} \mathrm{C} / \mathrm{min}$ up to the specified temperature (i.e., 500,600 , and $700{ }^{\circ} \mathrm{C}$, respectively). Similarly to the procedures in the impregnation with $\mathrm{KOH}$, the AC product was poured into $3 \mathrm{~N} \mathrm{HCl}$ solution, then heated at about $75{ }^{\circ} \mathrm{C}$ for $30 \mathrm{~min}$ and finally rinsed with deionized water $\left(150 \mathrm{~cm}^{3}\right)$ three times to remove the residual $\mathrm{KOH}$ and inherent ash minerals effectively. Prior to the determination of pore properties, the resulting $\mathrm{AC}$ products (denoted as CM-AC-500, CM-AC-600 and CM-AC-700) were dried at about $105^{\circ} \mathrm{C}$ for $24 \mathrm{~h}$.

\subsection{Characterization of Resulting and Commercial ACs}

The pore properties of the resulting AC (CM-AC) products and the commercial AC (Filtrasorb-300) were determined by its $\mathrm{N}_{2}$ adsorption-desorption isotherms at the temperature of liquid nitrogen (i.e., $-196{ }^{\circ} \mathrm{C}$ ) on the Micromeritics ASAP 2020 accelerated surface area and porosimetry system. Based on the analytical methods applied, the types of pore characterization included specific surface area, pore volume and pore size. For example, the specific surface area of the resulting AC can be obtained using the Brunauer-Emmett-Teller (BET) method in the relative pressure $\left(\mathrm{P} / \mathrm{P}_{0}\right)$ range of $0.05-0.30$. The total pore volume is indicative of the liquid nitrogen amount adsorbed at $\mathrm{P} / \mathrm{P}_{0}$ of about 0.99 [41]. According to the values of the BET surface area and total pore volume, the mean pore diameter or width can be further estimated by assuming the cylindrical geometry [42].

In order to elucidate the elemental compositions of AC on the surface, energy dispersive $X$-ray spectroscopy (Swift ED3000, Oxford Instruments, Abingdon, UK) was conducted to observe their contents of carbon, oxygen and other elements. The data could be associated with the interaction between the AC adsorbent and target adsorbate in the liquid-phase adsorption system. Using the potassium bromide (KBr) pellet technique, the Fourier infrared spectrometer (FT/IR-4600, JASCO Co., Tokyo, Japan) was further used to measure the functional groups on the surface of the resulting AC (CM-AC) and the commercial AC (Filtrasorb-300) in the range $4000-400 \mathrm{~cm}^{-1}$.

\subsection{Adsorption Performance Experiments}

Following the adsorption experiments referred to in a previous study [43], the batch adsorption kinetics of the CM-AC-700 were carried out in a 3-L mixing tank with four baffles. In the work, the data on the adsorption uptake of methylene blue (MB) by the MC-AC-700 from aqueous solution (2 liters) were obtained at the fixed solution temperature of $25^{\circ} \mathrm{C}$ and agitation speed of $200 \mathrm{rpm}$ under the determining adsorption process parameters, including initial $\mathrm{MB}$ concentrations (i.e., $\mathrm{C}_{0}=5$, 10,15 and $20 \mathrm{mg} / \mathrm{L}$ ) and $\mathrm{AC}$ dosages (i.e., $0.1,0.3$ and $0.5 \mathrm{~g}$, based on the solution volumes of $2 \mathrm{~L}$, which were abbreviated by $0.1,0.3$ and $0.5 \mathrm{~g} / 2 \mathrm{~L}$ ). During the adsorption experiments, an aliquot solution (about $10 \mathrm{~cm}^{3}$ ) was taken out at specified intervals (i.e., 5, 10, 20, 30, 40, 50 and $60 \mathrm{~min}$ ). 
After filtrating with mixed cellulose esters membrane filter with a size of $25 \mathrm{~mm}$, the analysis of dye concentration (i.e., $C_{t}$ ) in the remaining filtrate solution was immediately measured with a UV/Visible spectrophotometer (U-2900, Hitachi Co., Tokyo, Japan) at the maximum absorption wavelength (i.e., $661 \mathrm{~nm}$ ). It should be noted that about half of the solution sample after the filtration was first discarded to dye the filter completely. The adsorbed amount of MB $\left(q_{t}, \mathrm{mg} / \mathrm{g}\right)$ was obtained by the AC mass, solution volume (i.e., $2 \mathrm{~L}$ ), and the difference between $\mathrm{C}_{0}$ and $\mathrm{C}_{\mathrm{t}}$. On the other hand, this work also compared the adsorption performance of a commercial AC (i.e., Filtrasorb-300) with the CM-AC-700. The adsorption conditions were fixed at an initial MB concentration of $10 \mathrm{mg} / \mathrm{L}$, AC dosage of $0.3 \mathrm{~g} / 2 \mathrm{~L}$, agitation speed of $200 \mathrm{rpm}$, and temperature of $25^{\circ} \mathrm{C}$.

\section{Results and Discussion}

\subsection{Pore Properties of Resulting and Commercial ACs}

Table 1 listed the pore properties of the resulting ACs (CM-AC) and commercial AC (Filtrasorb 300), including surface area, pore volume and average pore diameter. Obviously, an increase in the activation temperature created the higher pore properties due to the development of more micropores. In addition, CM-AC-700 possessed favorable pore properties by comparison with Filtrasorb-300. For instance, the BET surface area of CM-AC-700 (i.e., $946 \mathrm{~m}^{2} / \mathrm{g}$ ) is slightly higher than that of Filtrasorb-300 (i.e., $660 \mathrm{~m}^{2} / \mathrm{g}$ ). Based on the data of surface area, regardless of the calculation methods, the ratio of that of Filtrasorb-300 to that of CM-AC-700 is close to 0.70. Using the data of total pore volume, the ratio of that of Filtrasorb-300 to that of CM-AC-700 was 0.68 , close to 0.70 . This result gave an indication of the pore size difference between CM-AC-700 and Filtrasorb-300. As mentioned above, we confidently inferred that the contribution to total pore volume of Filtrasorb-300 should be mostly from micropores. These results were in accordance with their average pore diameters (3.04 vs. $2.32 \mathrm{~nm}$, listed in Table 1). As shown in Table 1, the BET surface area values of the resulting AC products (CM-AC-600 and CM-AC-700) are higher than that $\left(445 \mathrm{~m}^{2} / \mathrm{g}\right)$ of biomass-based AC prepared from plant (Jatropha curcas L.) root with similar $\mathrm{KOH}$ activation conditions [44]. For large adsorbate molecules having similar dimensions to MB, CM-AC-700 could be preferable to remove them from the aqueous system due to the steric sizes of adsorbate molecules [45].

Table 1. Pore properties of resulting activated carbons (ACs), cow manure-derived activated carbon (CM-AC) and commercial AC (Filtrasorb-300).

\begin{tabular}{|c|c|c|c|c|}
\hline Property & CM-AC-500 & CM-AC-600 & CM-AC-700 & Filtrasorb-300 \\
\hline Single point surface area $\left(\mathrm{m}^{2} / \mathrm{g}\right)^{a}$ & 385.0 & 634.0 & 912.6 & 643.0 \\
\hline BET surface area $\left(\mathrm{m}^{2} / \mathrm{g}\right)$ & 383.3 & 627.9 & 946.3 & 660.0 \\
\hline Langmuir surface area $\left(\mathrm{m}^{2} / \mathrm{g}\right)$ & 576.0 & 935.9 & 1297.6 & 934.6 \\
\hline Micropore surface area $\left(\mathrm{m}^{2} / \mathrm{g}\right)^{\mathrm{c}}$ & 212.8 & 425.5 & 673.8 & 499.4 \\
\hline External surface area $\left(\mathrm{m}^{2} / \mathrm{g}\right) \mathrm{d}$ & 170.5 & 202.4 & 272.5 & 160.6 \\
\hline Total pore volume $\left(\mathrm{cm}^{3} / \mathrm{g}\right){ }^{\mathrm{e}}$ & 0.371 & 0.560 & 0.719 & 0.382 \\
\hline Micropore volume $\left(\mathrm{cm}^{3} / \mathrm{g}\right)^{\mathrm{c}}$ & 0.113 & 0.223 & 0.330 & 0.250 \\
\hline Pore diameter $(\AA)^{f}$ & 38.7 & 35.7 & 30.4 & 23.2 \\
\hline
\end{tabular}

${ }^{a}$ Obtained at relative pressure $\left(\mathrm{P} / \mathrm{P}_{0}\right)$ of about $0.30 .{ }^{b}$ Calculated in the range $0.05<$ relative pressure $\left(\mathrm{P} / \mathrm{P}_{0}\right)<0.30$.

${ }^{c}$ Micropore area by $t$-plot method. ${ }^{d}$ Obtained by subtracting micropore surface area from Brunauer-Emmett-Teller (BET) surface area. ${ }^{e}$ Total pore volume obtained at relative pressure $\left(\mathrm{P} / \mathrm{P}_{0}\right)$ of about $0.99 .{ }^{f}$ Obtained from the values of total pore volume and BET surface area.

To describe pore structures of the AC studied, the adsorption-desorption isotherms of nitrogen $\left(\mathrm{N}_{2}\right)$ at liquid nitrogen temperature (i.e., $-196^{\circ} \mathrm{C}$ ) is the commonly used method [41]. Figure 1 showed the $\mathrm{N}_{2}$ adsorption-desorption isotherms of CM-AC-700 and Filtrasorb-300. Obviously, these ACs belonged to type I isotherms due to their microporous feature (i.e., pore width $<2 \mathrm{~nm}$ ) [46]. Because of its high potential for adsorption, the micropore filling occurs significantly at $\mathrm{P} / \mathrm{P}_{0}$ of $<0.05$ [46]. On the other hand, the hysteresis loops occurred at the isotherms from the adsorption to desorption 
route, especially for CM-AC-700. It is well known that the loop is associated with mesoporous solids, where capillary condensation occurs at higher relative pressures. As listed in Table 1, these isotherms (Figure 1) also confirmed that CM-AC-700 has larger pore properties with wider pore size in comparison with Filtrasorb-300. Furthermore, the hysteresis loop pattern can be correlated with corresponding pore shapes. According to the classification of adsorption hysteresis loops recommended by the International Union of Pure and Applied Chemistry (IUPAC), the isotherms in Figure 1 belong to the type H4 loops [41], which are given by many ACs and some other microporous adsorbents with slit-shaped pores.

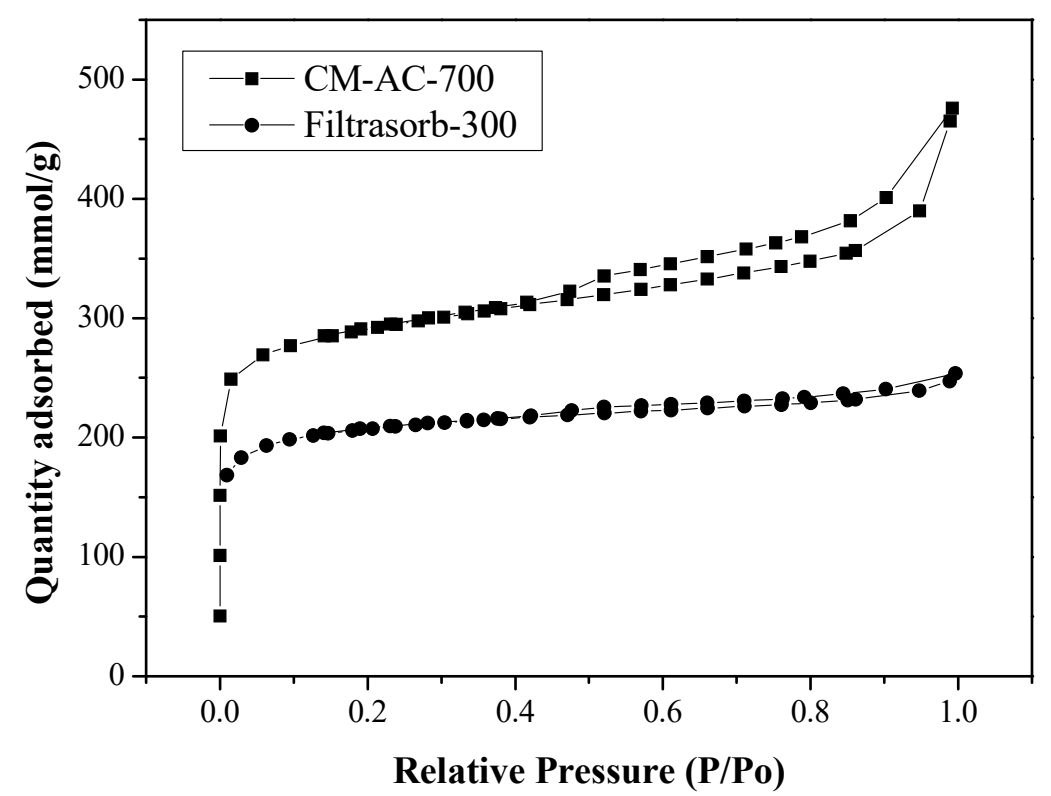

Figure 1. $\mathrm{N}_{2}$ adsorption-desorption isotherms of cow manure-derived activated carbon (CM-AC) and commercial activated carbon (i.e., Filtrasorb-300).

\subsection{Adsorption Performances of AC}

Figures 2 and 3 show the adsorption performances of CM-AC-700 for MB removal at the specific adsorption conditions under various initial $\mathrm{MB}$ concentrations and $\mathrm{AC}$ dosages, respectively. Obviously, the fast decrease in residual $\mathrm{MB}$ concentrations $\left(\mathrm{C}_{\mathrm{t}} / \mathrm{C}_{0}\right)$ occurred at a limited time. It implies that strong interactions between the cationic dye and the resulting $\mathrm{AC}$ exist. In this work, the pseudo-second order model was used to fit the adsorption system [47]. In order to fit the adsorption kinetic data, its linear form can be expressed as:

$$
t / q_{t}=1 /\left(k \times q_{e}^{2}\right)+\left(1 / q_{e}\right) \times t
$$

where $q_{t}$ is the adsorbed amount of MB at time $t(\mathrm{mg} / \mathrm{g}), q_{e}$ is the adsorbed amount of MB fitted at equilibrium $(\mathrm{mg} / \mathrm{g}), k$ is the rate constant $(\mathrm{g} /(\mathrm{mg} \cdot \mathrm{min}))$, and $t$ is the time (min). Furthermore, the time required for the adsorbent (i.e., $\mathrm{CM}-\mathrm{AC}$ ) to take up half as much adsorbate (i.e., $\mathrm{MB}$ ) as occurs at equilibrium (i.e., $t=t_{1 / 2}$ as $q_{t}=q_{e} / 2$ ) can be obtained by the following equation.

$$
t_{1 / 2}=1 /\left(k \times q_{e}\right)
$$




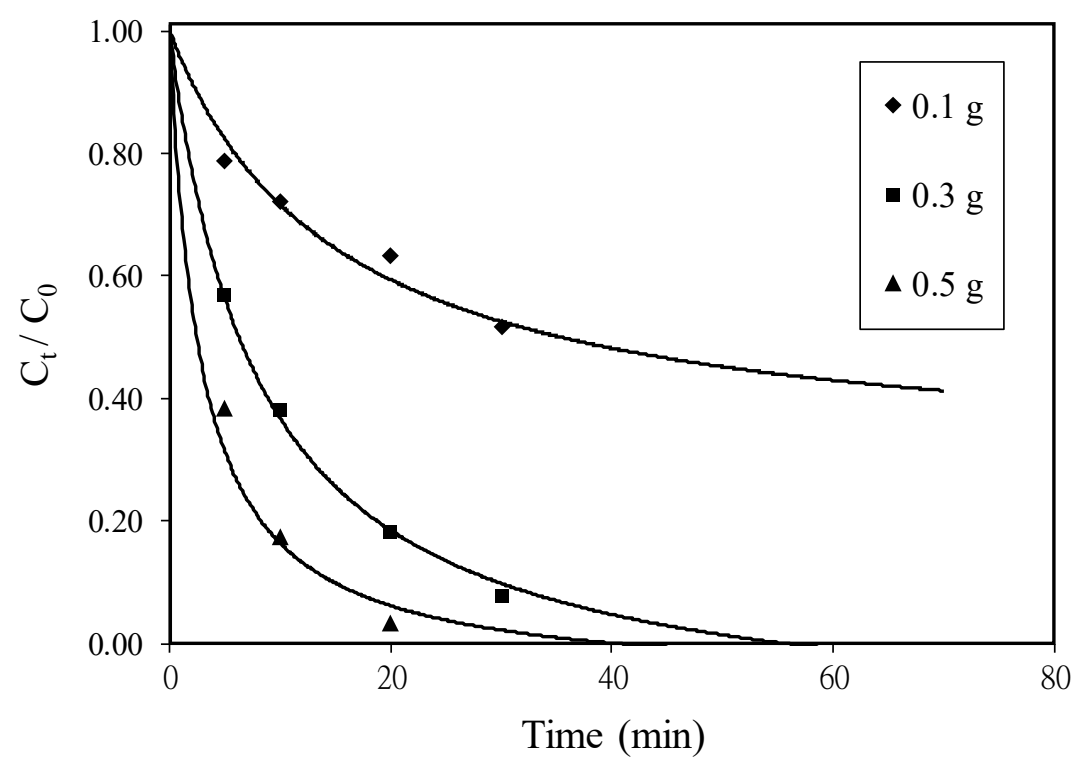

Figure 2. Effect of adsorbent CM-AC-700 dosage on methylene blue (MB) adsorption (initial MB concentrations $=10 \mathrm{mg} / \mathrm{L}$, agitation speed $=200 \mathrm{rpm}$, and temperature $=25^{\circ} \mathrm{C}$ ); symbols: measurement data, full lines: calculated from the fitted values (Table 2).

Table 2. Kinetic parameters for methylene blue (MB) adsorption onto adsorbent CM-AC-700 at various adsorbent dosages based on pseudo-second order model ${ }^{\text {a }}$.

\begin{tabular}{|c|c|c|c|c|}
\hline Adsorbent Dosage (g/2 L) & $k(\mathrm{~g} / \mathrm{mg} \cdot \mathrm{min})$ & $q_{e}(\mathrm{mg} / \mathrm{g})$ & Correlation Coefficient & $t_{1 / 2}(\min )$ \\
\hline 0.1 & 0.0005 & 142.86 & 0.987 & 14.0 \\
\hline 0.3 & 0.0016 & 76.34 & 0.999 & 8.2 \\
\hline 0.5 & 0.0084 & 42.74 & 0.999 & 2.8 \\
\hline
\end{tabular}

a Adsorption conditions: initial MB concentration $=10 \mathrm{mg} / \mathrm{L}$, agitation speed $=200 \mathrm{rpm}$, and temperature $=25^{\circ} \mathrm{C}$.

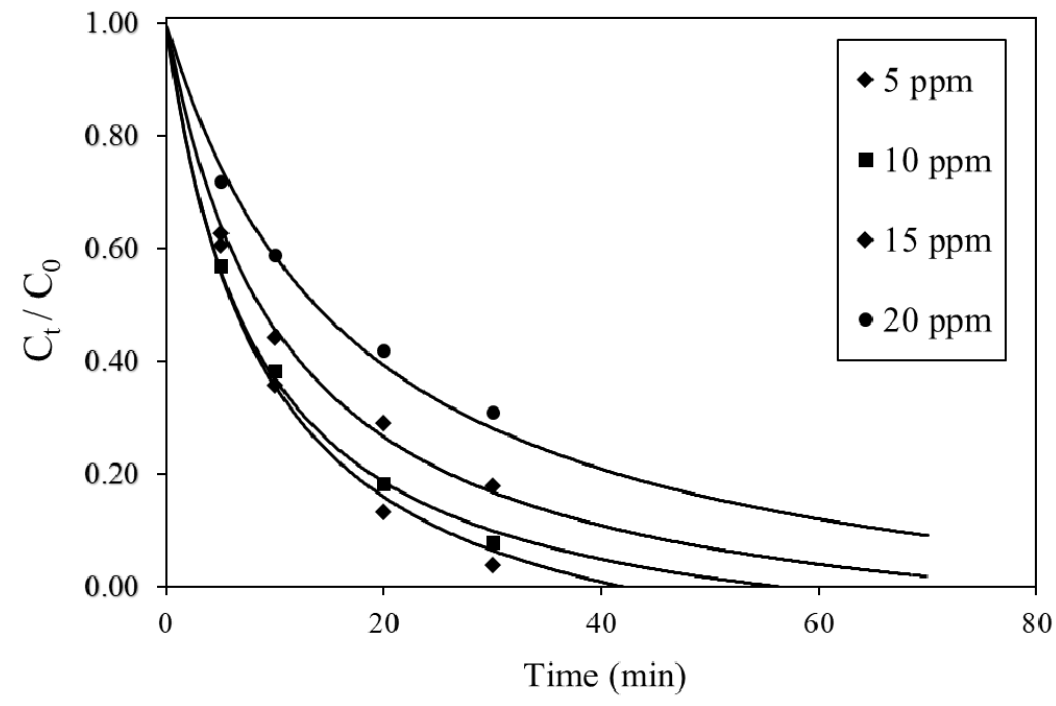

Figure 3. Effect of initial MB concentration on MB adsorption; adsorption conditions: adsorbent CM-AC-700 dosage $=0.3 \mathrm{~g} / 2 \mathrm{~L}$, adsorption temperature $=25^{\circ} \mathrm{C}$, and agitation speed $=200 \mathrm{rpm}$; symbols: measurement data, full lines: calculated from the fitted values (Table 3). 
Table 3. Kinetic parameters for methylene blue (MB) adsorption onto adsorbent CM-AC-700 at initial MB concentrations based on pseudo-second order model ${ }^{\mathrm{a}}$.

\begin{tabular}{ccccc}
\hline Initial MB Concentration $(\mathbf{m g} / \mathbf{L})$ & $\boldsymbol{k}(\mathrm{g} / \mathbf{m g} \cdot \mathbf{m i n})$ & $\boldsymbol{q}_{\boldsymbol{e}}(\mathbf{m g} / \mathbf{g})$ & Correlation Coefficient & $\boldsymbol{t}_{\mathbf{1 / 2}}(\mathbf{m i n})$ \\
\hline 5 & 0.0028 & 40.32 & 0.993 & 8.9 \\
10 & 0.0016 & 76.34 & 0.999 & 8.2 \\
15 & 0.0008 & 113.64 & 0.999 & 11.0 \\
20 & 0.0004 & 151.52 & 0.996 & 16.5 \\
\hline
\end{tabular}

a Adsorption conditions: adsorbent MC-AC dosage $=0.3 \mathrm{~g} / 2 \mathrm{~L}$, agitation speed $=200 \mathrm{rpm}$, and temperature $=25^{\circ} \mathrm{C}$.

The fitted values of kinetic parameters for the adsorption system were listed in Tables 2 and 3. Obviously, the kinetics of MB adsorption into CM-AC followed this model with high correlation coefficients $(>0.99)$. As listed in Table 2, the fitted adsorption capacity (i.e., $q_{e}$ ) decreased as the initial MB concentration (i.e., $\mathrm{C}_{0}$ ) increased. The decrease of $q_{e}$ with increasing adsorbent dosage implies the exhaustion of adsorption onto excessive adsorbent due to the limited MB molecules. On the other hand, the rate constant values significantly increased at higher adsorbent dosage because of the increase in more adsorption sites provided. This result agrees with previous studies with relation to the adsorption of dyes onto activated carbon and clay $[45,48,49]$. On the other hand, the fitted adsorption capacity (seen in Table 3) indicated an increasing trend as the initial MB concentration (i.e., $\mathrm{C}_{0}$ ) increased. This result can be expected because more adsorbate molecules were adsorbed at the equilibrium condition onto the adsorbent without exhausting its adsorption.

Figure 4 shows the adsorption kinetic profiles of CM-AC-700 in comparison with that of the commercial AC at the same conditions, that is, initial MB concentration of $10 \mathrm{mg} / \mathrm{L}, \mathrm{CM}-\mathrm{AC}-700$ dosage of $0.3 \mathrm{~g} / 2 \mathrm{~L}$, agitation speed of $200 \mathrm{rpm}$, and temperature of $25^{\circ} \mathrm{C}$. As listed in Table $4, \mathrm{CM}-\mathrm{AC}-700$ exhibited a better adsorption performance for the removal of $\mathrm{MB}$ from the aqueous solution as compared to the commercial AC (Filtrasorb-300). This difference between the fitted values of adsorption capacities (i.e., $q_{e}$ ) can be associated with the interactions between the adsorbate and the adsorbent, including the pore properties of the adsorbent for physical adsorption and the electrostatic attraction interaction between the cationic dye and the negatively charged surface [44]. The observations using energy dispersive X-ray spectroscopy (Figure 5) showed a higher content of oxygen on the CM-AC-700 surface in comparison with the adsorbent Filtrasorb-300, thus enhancing its polar nature (i.e., hydrophilicity, acidity) due to more oxygen complexes or groups on the surface [50]. These surface oxygen complexes and oxygen-containing functional groups (e.g., carboxylic, carbonyl, phenolic groups) could arise from its lignocellulosic constituents and ashes (consisting mainly of silica, alumina, alkaline and alkaline earth metals) in the starting materials (i.e., CM). The carbon contents of the resulting carbon materials were further analyzed using an elemental analyzer and showed a range from 60 to $65 \mathrm{wt} \%$, while that of the commercial activated carbon (Filtrasorb-300) demonstrated a range up to about $90 \mathrm{wt} \%$. These results were consistent with the energy dispersive X-ray spectroscopy analyses (Figure 5). Therefore, the interaction between the cationic dye (MB molecule) and the adsorbent CM-AC-700 via stronger van der Waals forces or other binding forms also plays a vital role in the liquid-phase adsorption. On the other hand, Figure 6 depicted the Fourier transform infrared spectroscopy (FTIR) spectra of CM-AC700 and Filtrasorb-300. The peaks of CM-AC-700 at about 3440, 2400, 1630, 1380, 1180 and $620 \mathrm{~cm}^{-1}$ could be mostly associated with functional groups containing oxygen (i.e., $\mathrm{O}-\mathrm{H}$, $\mathrm{C}=\mathrm{O}, \mathrm{C}-\mathrm{O}$ ) [51], which were more significant than those of Filtrasorb-300. For example, there is a broad absorption peak at $3440 \mathrm{~cm}^{-1}$ in the CM-AC-700, which is assigned to the stretching vibration of $\mathrm{O}-\mathrm{H}$. In addition, a sharp peak at about $3440 \mathrm{~cm}^{-1}$ may correspond to the bending band of $\mathrm{O}-\mathrm{H}$. The interaction between the cationic dye and the adsorbent CM-AC-700 via stronger van der Waals forces or other binding forms also plays a vital role in the adsorption process. 


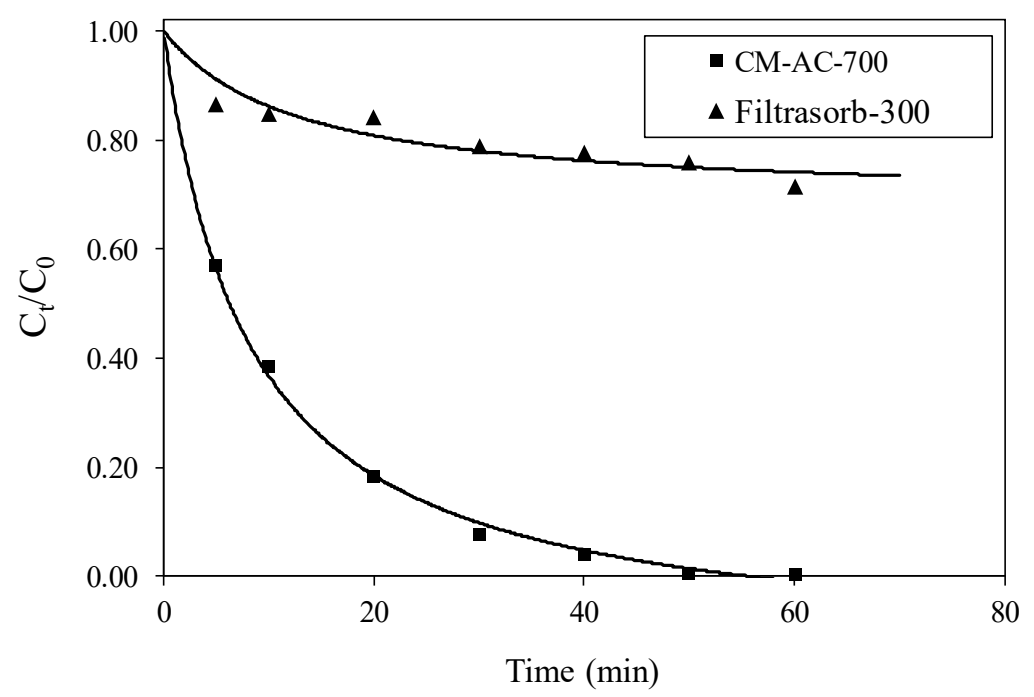

Figure 4. Effect of different $\mathrm{ACs}$ on $\mathrm{MB}$ adsorption; adsorption conditions: initial $\mathrm{MB}$ concentration $=10 \mathrm{mg} / \mathrm{L}$, adsorbent dosage $=0.2 \mathrm{~g} / 2 \mathrm{~L}$, adsorption temperature $=25^{\circ} \mathrm{C}$, and agitation speed $=200 \mathrm{rpm}$; symbols: experimental data, full lines: calculated from Equation (1) and Table 4.

Table 4. Kinetic parameters for methylene blue (MB) adsorption onto resulting AC (CM-AC-700) and commercial AC (Filtrasorb-300) based on pseudo-second order model ${ }^{\mathrm{a}}$.

\begin{tabular}{lcccc}
\hline Adsorbent & $\boldsymbol{k}(\mathrm{g} / \mathbf{m g} \cdot \mathbf{m i n})$ & $\boldsymbol{q}_{\boldsymbol{e}}(\mathbf{m g} / \mathrm{g})$ & Correlation Coefficient & $\boldsymbol{t}_{\mathbf{1 / 2}}(\mathbf{m i n})$ \\
\hline CM-AC-700 & 0.0016 & 76.34 & 0.999 & 8.2 \\
Filtrasorb-300 & 0.0038 & 20.88 & 0.944 & 12.6 \\
\hline
\end{tabular}

a Adsorption conditions: initial MB concentration $=10 \mathrm{mg} / \mathrm{L}$, adsorbent dosage $=0.3 \mathrm{~g} / 2 \mathrm{~L}$, agitation speed $=200 \mathrm{rpm}$, and temperature $=25^{\circ} \mathrm{C}$.

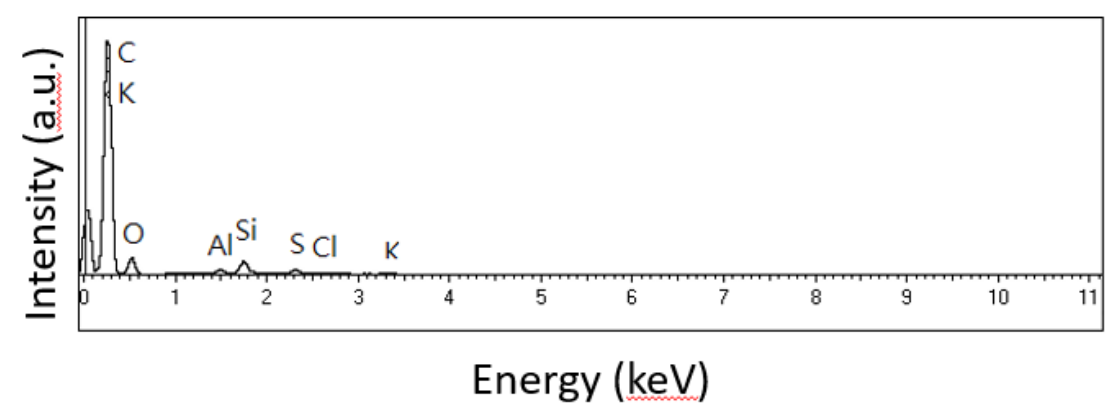

\begin{tabular}{ccc}
\hline Element & Weight $\%$ & Atomic $\%$ \\
\hline Carbon & 59.705 & 68.236 \\
Oxygen & 33.389 & 28.648 \\
Aluminum & 0.719 & 0.366 \\
Silicon & 3.386 & 1.655 \\
Sulfur & 1.209 & 0.518 \\
Chlorine & 0.523 & 0.202 \\
Potassium & 1.069 & 0.375 \\
\hline
\end{tabular}

(a) cow manure-derived activated carbon (CM-AC-700)

Figure 5. Cont. 


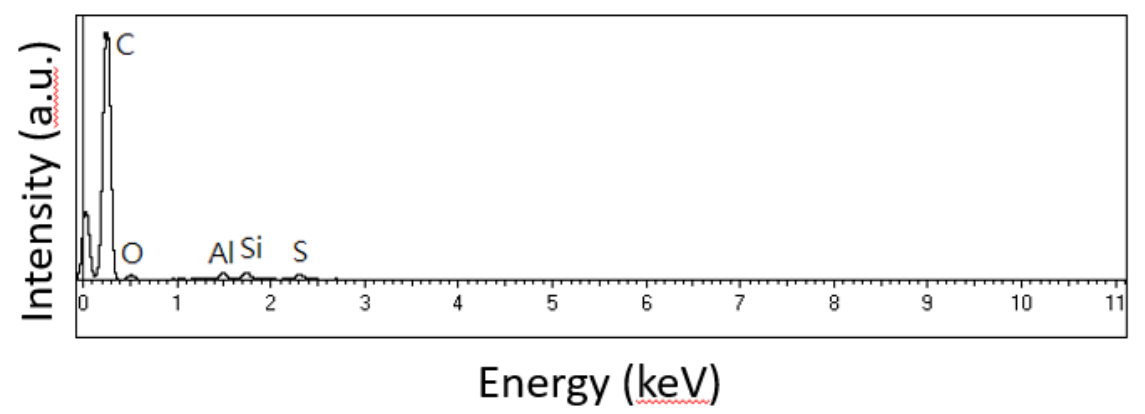

\begin{tabular}{ccc}
\hline Element & Weight $\%$ & Atomic\% \\
\hline Carbon & 89.628 & 93.069 \\
Oxygen & 7.319 & 5.706 \\
Aluminum & 0.821 & 0.379 \\
Silicon & 0.937 & 0.416 \\
Sulfur & 0.846 & 0.329 \\
Iron & 0.449 & 0.100 \\
\hline
\end{tabular}

(b) Commercial activated carbon (i.e., Filtrasorb-300)

Figure 5. Energy dispersive X-ray spectroscopy spectra of (a) CM-AC-700 and (b) Filtrasorb-300.

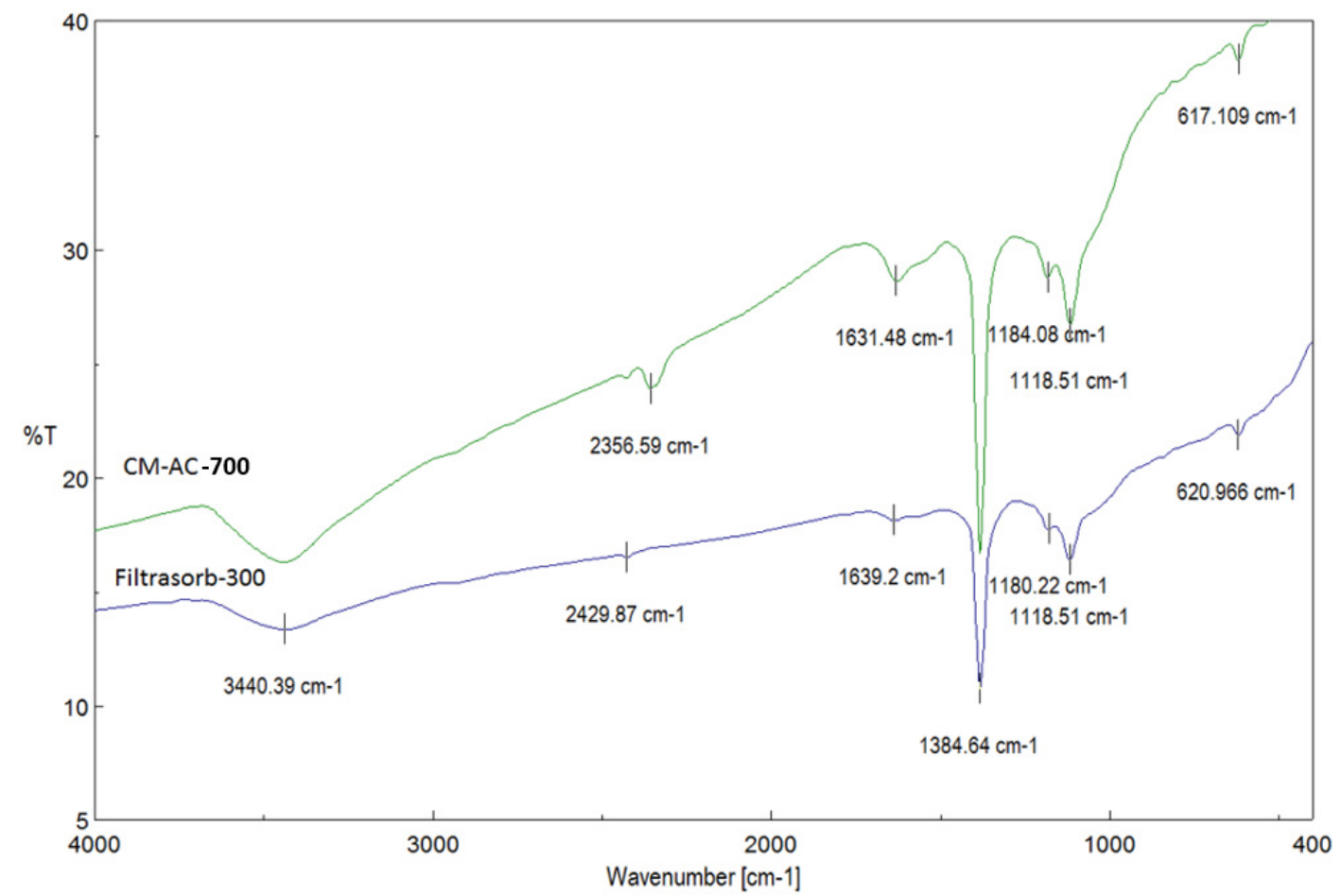

Figure 6. Fourier transform infrared spectroscopy (FTIR) spectra of CM-AC-700 and Filtrasorb-300.

\section{Conclusions}

The thermochemical conversion of cattle manure can be positively related to climate change mitigation (reduction of greenhouse gas emissions) and waste and wastewater management (improvement of environmental quality). In this work, based on the experimental results of the chemical, pore and adsorption properties for the resulting and commercial ACs, cattle (cow) manure could be an excellent precursor for producing AC at different temperatures (i.e., 500, 600 and $700{ }^{\circ} \mathrm{C}$ ) using a $\mathrm{KOH}$ activation process. The conclusions can be itemized as follows: 
- The nitrogen adsorption-desorption isotherms of the resulting ACs showed that an increase in the activation temperature created the higher pore properties due to the development of more micropores.

- The optimal AC product (i.e., CM-AC-700) showed its microporous feature with the pore properties of a BET surface area of $946 \mathrm{~m}^{2} / \mathrm{g}$ and total pore volume of about $0.72 \mathrm{~cm}^{3} / \mathrm{g}$, which are close to those of common commercial ACs.

- The resulting AC could be an effective low-cost adsorbent for the removal of cationic dye (i.e., methylene blue, MB) from aqueous solution based on the fittings of the pseudo-second order model.

- $\quad$ The resulting AC exhibited a better adsorption performance for the removal of MB from the aqueous solution as compared to the commercial AC.

- The cow manure-derived adsorbent has a stronger interaction due to its larger pore properties and more oxygen-containing complex on the surface based on the observations of energy dispersive X-ray spectroscopy and Fourier transform infrared spectroscopy (FTIR).

Author Contributions: Conceptualization, W.-T.T.; methodology, P.-C.H.; validation, P.-C.H.; data curation, Y.-Q.L.; formal analysis, Y.-Q.L; Writing-Original draft preparation, W.-T.T.; Writing-Review and editing, W.-T.T.

Funding: This research received no external funding.

Acknowledgments: The authors express sincere appreciation to the Instrument Center of National Pingtung University of Science and Technology for assistance with the energy dispersive X-ray spectroscopy (EDS) observation.

Conflicts of Interest: The authors declare no conflicts of interest.

\section{References}

1. Teodosiu, C.; Gilca, A.F.; Barjoveanu, G.; Fiore, S. Emerging pollutants removal through advanced drinking water treatment: A review on processes and environmental performances assessment. J. Clean. Prod. 2018, 197, 1210-1221. [CrossRef]

2. Hodaifa, G.; Callardo, P.A.R.; Garcia, C.A.; Kowalska, M.; Seyedsalehi, M. Chemical oxidation methods for treatment of real industrial olive oil mill wastewater. J. Taiwan Inst. Chem. Eng. 2019, 97, 247-254. [CrossRef]

3. Garcia, J.R.; Sedran, U.; Zaini, M.A.A.; Zakaria, Z.A. Preparation, characterization, and dye removal study of activated carbon prepared from palm kernel shell. Environ. Sci. Pollut. Res. 2018, 25, 5076-5085. [CrossRef] [PubMed]

4. Jeirani, Z.; Niu, C.H.; Soltan, J. Adsorption of emerging pollutants on activated carbon. Rev. Chem. Eng. 2017, 33, 491-522. [CrossRef]

5. Al-Ghouti, M.A.; Al-Kaabi, M.A.; Ashfag, M.Y.; Da'na, D.A. Produced water characteristics, treatment and reuse: A review. J. Water Process Eng. 2019, 28, 222-239. [CrossRef]

6. Loannidou, O.; Zabaniotou, A. Agricultural residues as precursors for activated carbon production-A review. Renew. Sustain. Energy Rev. 2007, 11, 1966-2005. [CrossRef]

7. Demirbas, A. Agricultural based activated carbons for the removal of dyes from aqueous solutions: A review. J. Hazard. Mater. 2009, 167, 1-9. [CrossRef]

8. Alslaibi, T.M.; Abustan, I.; Ahmad, M.A.; Foul, A.A. A review: Production of activated carbon from agricultural byproducts via conventional and microwave heating. J. Chem. Technol. Biotechnol. 2013, 88, 1183-1190. [CrossRef]

9. Abioye, A.M.; Ani, F.N. Recent development in the production of activated carbon electrodes from agricultural waste biomass for supercapacitors: A review. Renew. Sustain. Energy Rev. 2015, 52, 1282-1293. [CrossRef]

10. Yahya, M.A.; Al-Qodah, Z.; Ngah, C.W.Z. Agricultural bio-waste materials as potential sustainable precursors used for activated carbon production: A review. Renew. Sustain. Energy Rev. 2015, 46, 218-235. [CrossRef]

11. Gonzalez-Garcia, P. Activated carbon from lignocellulosics precursors: A review of the synthesis methods, characterization techniques and applications. Renew. Sustain. Energy Rev. 2018, 82, 1393-1414. [CrossRef]

12. Lu, Y.; Shan, G.; Huang, J.; Li, Q. Insights into characteristics of dissolved organic matter fractions in co-composted dairy manure and Chinese herbal residues. Waste Biomass Valor. 2018, 9, 777-782. [CrossRef] 
13. Cantrell, K.B.; Ducey, T.; Ro, K.S.; Hunt, P.G. Livestock waste-to-bioenergy generation opportunities. Bioresour. Technol. 2008, 99, 7941-7953. [CrossRef] [PubMed]

14. Dagnall, S.; Hill, J.; Pegg, D. Resource mapping and analysis of farm livestock manures-assessing the opportunities for biomass-to-energy schemes. Bioresour. Technol. 2000, 71, 225-234. [CrossRef]

15. Raven, R.P.J.M. Implementation of manure digestion and co-combustion in the Dutch electricity regime: A multi-level analysis of market implementation in the Netherlands. Energy Policy 2004, 32, 29-39. [CrossRef]

16. Carlin, N.; Annamalai, K.; Sweeten, J.; Mukhtar, S. Thermo-chemical conversion analysis on dairy manure-based biomass through direct combustion. Int. J. Green Energy 2007, 4, 133-159. [CrossRef]

17. Cantrell, K.B.; Hunt, P.G.; Uchimiya, M.; Novak, J.M.; Ro, K.S. Impact of pyrolysis temperature and manure source on physicochemical characteristics of biochar. Bioresour. Technol. 2012, 107, 419-428. [CrossRef]

18. Fernandez-Lopez, M.; Puig-Gamero, M.; Lopez-Gonzalez, D.; Avalos-Ramirez, A.; Valverde, J.; Sanchez-Silva, L. Life cycle assessment of swine and dairy manure: Pyrolysis and combustion processes. Bioresour. Technol. 2015, 182, 184-192. [CrossRef]

19. Kim, J.K.; Kim, H.S.; Park, S.U.; Lee, H.D.; Kim, S.C. Combustion possibility of cattle manure as a blended fuel of pulverized coal fired power plant using TGA and $100 \mathrm{~kg} / \mathrm{h}$ test furnace. J. Chem. Eng. Jpn. 2015, 48, 307-319. [CrossRef]

20. Yi, B.J.; Yuan, Q.X.; Cao, H.L.; Niu, W.J.; Wang, M.; Zhu, Y.; Yan, S.P. Effect of alkali and alkaline earth metal species on the combustion characteristics of cattle manures. RSC Adv. 2018, 8, 11705-11713. [CrossRef]

21. Xu, X.Y.; Cao, X.D.; Zhao, L.; Wang, H.L.; Yu, H.R.; Gao, B. Removal of $\mathrm{Cu}, \mathrm{Zn}$, and Cd from aqueous solutions by the dairy manure-derived biochar. Environ. Sci. Pollut. Res. 2013, 20, 358-368. [CrossRef] [PubMed]

22. Cao, H.L.; Xin, Y.; Yuan, Q.X. Prediction of biochar yield from cattle manure pyrolysis via least squares support vector machine intelligent approach. Bioresour. Technol. 2016, 202, 158-164. [CrossRef] [PubMed]

23. Ma, F.F.; Zhao, B.W.; Diao, J.R.; Qiao, H.T.; Zhong, J.K. Sorption of cadmium by biochar produced from pyrolysis of cattle manure in aqueous solution. Fresen. Environ. Bull. 2016, 25, 5226-5236.

24. Zhu, Y.; Yi, B.J.; Yuan, Q.X.; Wang, M.; Yan, S.P. Removal of methylene blue from aqueous solution by cattle manure-derived low temperature biochar. RSC Adv. 2018, 8, 19917-19929. [CrossRef]

25. Chen, Z.L.; Zhang, J.Q.; Huang, L.; Yuan, Z.H.; Li, Z.J.; Liu, M.C. Removal of Cd and Pb with biochar made from dairy manure at low temperature. J. Integr. Agric. 2019, 18, 201-210. [CrossRef]

26. Tsai, T.W.; Hsu, C.H.; Lin, Y.Q. Highly porous and nutrients-rich biochar derived from dairy cattle manure and its potential for removal of cationic compound from water. Agriculture 2019, 9, 114. [CrossRef]

27. Klass, D.J. Biomass for Renewable Energy, Fuels, and Chemicals; Academic Press: San Diego, CA, USA, 1998.

28. Qian, Q.R.; Machida, M.; Tatsumoto, H. Preparation of activated carbons from cattle-manure compost by zinc chloride activation. Bioresour. Technol. 2007, 98, 353-360. [CrossRef]

29. Qian, Q.R.; Machida, M.; Aikawa, M.; Tatsumoto, H. Effect of $\mathrm{ZnCl}_{2}$ impregnation ratio on pore structure of activated carbons prepared from cattle manure compost: Application of $\mathrm{N}_{2}$ adsorption-desorption isotherms. J. Mater. Cycles Waste Manag. 2008, 10, 53-61. [CrossRef]

30. Qian, Q.R.; Machida, M.; Tatsumoto, H. Textural and surface chemical characteristics of activated carbons prepared from cattle manure compost. Waste Manag. 2008, 28, 1064-1071. [CrossRef]

31. Qian, Q.R.; Sunohara, S.; Kato, Y.; Zaini, M.A.A.; Machida, M.; Tatsumoto, H. Water vapor adsorption onto activated carbons prepared from cattle manure compost. Appl. Surf. Sci. 2008, 254, 4868-4874. [CrossRef]

32. Qian, Q.R.; Chen, Q.H.; Machida, M.; Tatsumoto, H.; Mochidzuki, K.; Sakoda, A. Removal of organic contaminants from aqueous solution by cattle manure compost (CMC) derived activated carbons. Appl. Surf. Sci. 2009, 255, 6107-6114. [CrossRef]

33. Zaini, M.A.A.; Amano, Y.; Machida, M. Removal of lead (II) binding properties of heat-treated cattle-manure-compost-activated carbons. Desalin. Water Treat. 2014, 52, 6420-6429. [CrossRef]

34. Zaini, M.A.A.; Okayama, R.; Machida, M. Adsorption of aqueous metal ions on cattle-manure-compost based activated carbons. J. Hazard. Mater. 2009, 170, 1119-1124. [CrossRef] [PubMed]

35. Watanabe, T.; Zaini, M.A.A.; Amano, Y.; Machida, M. Removal of 2-methylisoborneol from aqueous solution by cattle manure compost (CMC) derived activated carbons. J. Water Supply Res. Technol.-AQUA 2014, 63, 239-247. [CrossRef]

36. Li, H.C.; Yang, S.S.; Sun, H.Z.; Liu, X.H. Production of activated carbon from cow manure for wastewater treatment. BioResources 2018, 13, 3135-3143. [CrossRef] 
37. Marsh, H.; Rodriguez-Reinoso, F. Activated Carbon; Elsevier: Amsterdam, The Netherlands, 2006.

38. Ge, C.; Lian, D.; Cui, S.; Gao, J.; Lu, J. Highly selective $\mathrm{CO}_{2}$ capture on waste polyurethane foam-based activated carbon. Processes 2019, 7, 592. [CrossRef]

39. Liu, S.C.; Tsai, W.T. Thermochemical characteristics of dairy manure and its derived biochars from a fixed-bed pyrolysis. Int. J. Green Energy 2016, 13, 963-968. [CrossRef]

40. Tsai, T.W.; Chang, C.Y.; Wang, S.Y.; Chang, C.F.; Chien, S.F.; Sun, H.F. Preparation of activated carbons from corn cob catalyzed by potassium salts and subsequent gasification with $\mathrm{CO}_{2}$. Bioresour. Technol. 2001, 78, 203-208. [CrossRef]

41. Lowell, S.; Shields, J.E.; Thomas, M.A.; Thommes, M. Characterization of Porous Solids and Powders: Surface Area, Pore Size and Density; Springer: Dordrecht, The Netherlands, 2006.

42. Smith, J.M. Chemical Engineering Kinetics, 3rd ed.; McGraw-Hill: New York, NY, USA, 1981.

43. Tsai, W.T.; Hsu, H.C.; Su, T.Y.; Lin, K.Y.; Lin, C.M.; Dai, T.H. The adsorption of cationic dye from aqueous solution onto acid-activated andesite. J. Hazard. Mater. 2007, 147, 1056-1062. [CrossRef]

44. Alvarez-Mateos, P.; Garcia-Martin, T.F.; Guerrero-Vacas, F.J.; Maranjo-Calderon, C.; Barrios-Sanchez, C.C.; Perez-Camino, M.C. Valorization of a high-acidity residual oil generated in the waste cooking oils recycling industries. Grasas Aceites 2019, 70, 335. [CrossRef]

45. Tamai, H.; Yoshida, T.; Sasaki, M.; Yasuda, H. Dye adsorption on mesoporous activated carbon fiber obtained from pitch containing yttrium complex. Carbon 1999, 37, 983-989. [CrossRef]

46. Gregg, S.J.; Sing, K.S.W. Adsorption, Surface Area, and Porosity; Academic Press: London, UK, 1982.

47. Ho, Y.S.; Chiang, C.C.; Hsu, Y.C. Sorption kinetics for dye removal from aqueous solution using activated clay. Sep. Sci. Technol. 2001, 36, 2473-2488. [CrossRef]

48. Demirbas, E.; Kobya, M.; Sulak, M.T. Adsorption kinetics of a basic dye from aqueous solutions onto apricot stone activated carbon. Bioresour. Technol. 2008, 99, 5368-5373. [CrossRef] [PubMed]

49. Ghaedi, M.; Golestani Nasab, A.; Khodadoust, S.; Rajabi, M.; Azizian, S. Application of activated carbon as adsorbents for efficient removal of methylene blue: Kinetics and equilibrium study. J. Ind. Eng. Chem. 2014, 20, 2317-2324. [CrossRef]

50. Suzuki, M. Adsorption Engineering; Elsevier: Amsterdam, The Netherlands, 1990.

51. Islam, M.S.; Ang, B.C.; Gharehkhani, S.; Afifi, A.B.M. Adsorption capability of activated carbon synthesized from coconut shell. Carbon Lett. 2016, 20, 1-9. [CrossRef] 